\title{
Speed control of sensorless BLDC motor with two side chopping PWM
}

\author{
Anju Roy ${ }^{1}$, Dominic Mathew ${ }^{2}$ \\ ${ }^{1}$ (Department of EEE, Rajagiri School of Engineering Kakkanad, India) \\ ${ }^{2}$ (Department f AEI, Rajagiri School of Engineering Kakkanad, India)
}

\begin{abstract}
The Brushless Direct Current (BLDC) motors are one of the motor types rapidly gaining popularity. BLDC motors are used in aerospace applications, medical field, industrial automation equipment and instrumentation. As the name implies, BLDC motors do not use brushes for commutation; instead, they are electronically commutated. This paper proposes a new optimized sensorless drive for speed control of BLDC motor, which is based on back-EMF zero crossing detection (ZCD) of only one phase voltage of BLDC motor. This commutation technique of BLDC motor significantly reduces sensing circuits and cost of motor drive. The effectiveness of proposed speed control for sensorless technique is verified through simulation. Two side chopping PWM technique with a PI duty cycle controller is used for speed control.

Keywords - BLDC, PI controller, PWM, ZCD, VSI
\end{abstract}

\section{INTRODUCTION}

Brushless Direct Current (BLDC) motors are one of the motor types rapidly gaining popularity. BLDC motor has been used extensively in industrial automation, aerospace, instrumentation and automotive industries since 1970's. As the name implies, BLDC motors do not use brushes for commutation; instead, they are electronically commutated. BLDC motors have many advantages over brushed DC motors and induction motors. A few of these are:

- Better speed versus torque characteristics

- High dynamic response

- High efficiency

- Long operating life

- Noiseless operation

- Higher speed ranges

In addition, the ratio of torque delivered to the size of the motor is higher, making it useful in applications where space and weight are critical factors.

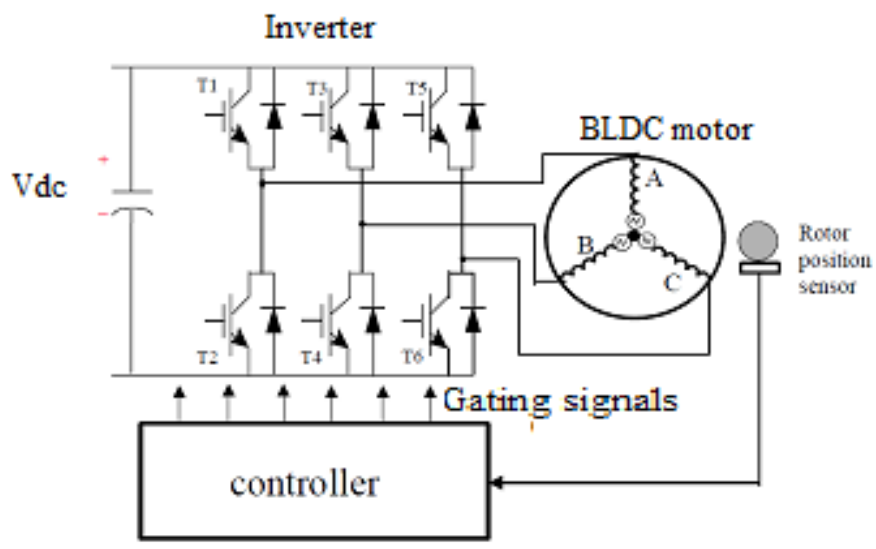

Fig. 1.BLDC motor control system with position sensors.

These BLDC motors are generally controlled using a three-phase inverter, requiring a rotor position sensor for starting. The three phase inverter provides proper commutation sequence for the speed control of BLDC motor. The position sensors will increase the cost and the size of the motor, and a special mechanical arrangement needs to be made for mounting the sensors. They could reduce the system reliability due to increased number of the components and hardware interfacing. The position sensors can be Hall sensors, 
resolvers or absolute position sensors. Hall sensors are particularly temperature sensitive, limiting the operation of the motor to below $75^{\circ} \mathrm{C}$. In some applications, it even may not be possible to mount any position sensor on the motor. Therefore, sensorless control of BLDC motor has been receiving great interest in recent years.

Typically, a Brushless dc motor is driven by a three-phase inverter with six-step commutation. The conducting interval for each phase is $120^{\circ}$ by electrical angle. The commutation phase sequence is AB-AC-BCBA-CA-CB. Each conducting stage is called one step. Therefore, only two phases conduct current at any time, leaving the third phase floating. In order to produce maximu m torque, the inverter should be commutated every $60^{\circ}$ so that current is in phase with the back EMF. The commutation timing is determined by the rotor position, which can be detected by Hall sensors or estimated from motor parameters, i.e., the back EMF on the floating coil of the motor if it is sensorless system.

Basically two types of sensorless control schemes can be found in the literature based on,

1) Position sensing using back EMF of the motor, and

2) Position estimation using motor parameters, terminal voltages, and currents.

The second type scheme usually needs Digital Signal Processors to do the complicated computation, and the cost of the system is relatively high. So the back EMF sensing type of sensorless scheme is the most commonly used method.

In brushless dc motor, only two out of three phases are excited at one time, leaving the third winding floating. The back EMF voltage in the floating winding can be measured to establish a switching sequence for commutation of power devices in the three-phase inverter. Back-EMF sensing methods rely on the zero crossing detection of the measured voltage signal. Back EMF of each phase is measured through the line voltage of same phase of motor with respect to negative terminal of three phase voltage source inverter (VSI) DC power supply.

\section{SENSORLESS CONTROL}

$\mathrm{V}_{\mathrm{a}}, \mathrm{V}_{\mathrm{b}}, \mathrm{V}_{\mathrm{c}}$ are referred to the terminal voltages of BLDC motor, $\mathrm{Vn}$ is the neutral point voltage and $\mathrm{V}_{\mathrm{DC}}$ is the DC bus voltage of inverter. $\mathrm{R}$ and $\mathrm{L}$ are resistance and inductance of stator windings which is assumed to be constant for all phases. The magnetic circuit saturation and losses in motor are also ignored. At each instant of time only two phases out of three phases of stator are conducting. Therefore back-EMF can be detected from the floating terminal voltage. Consider phase $\mathrm{B}$ and phase $\mathrm{C}$ are conducting and phase $\mathrm{A}$ is floating phase $\left(\mathrm{i}_{\mathrm{b}}=-\right.$ $\mathrm{i}_{\mathrm{c}}$ and $\mathrm{i}_{\mathrm{a}}=0$ ). Then voltage terminal equations can be written as,

$$
\begin{aligned}
& \mathrm{V}_{\mathrm{a}}=\mathrm{E}_{\mathrm{a}}+\mathrm{V}_{\mathrm{n}} \\
& \mathrm{V}_{\mathrm{b}}=\mathrm{Ri}_{\mathrm{b}}+\mathrm{Ldi} / \mathrm{dt}+\mathrm{E}_{\mathrm{b}}+\mathrm{V}_{\mathrm{n}} \\
& \mathrm{V}_{\mathrm{c}}=\mathrm{Ri}_{\mathrm{c}}+\mathrm{Ldi} / \mathrm{dt}+\mathrm{E}_{\mathrm{c}}+\mathrm{V}_{\mathrm{n}}
\end{aligned}
$$

Where $i_{b}=-i_{c}, E_{b}=-E_{c}$ and $V_{b}+V_{c}=V_{D C}$. There fore by adding (3) and (2) neutral point voltage is,

$$
\mathrm{V}_{\mathrm{n}}=\mathrm{V}_{\mathrm{DC}} / 2
$$

Substituting (4) in (1) floating point terminal voltage can be written as,

$\mathrm{V}_{\mathrm{a}}=\mathrm{E}_{\mathrm{a}}+\mathrm{V}_{\mathrm{DC}} / 2$

If $\mathrm{E}_{\mathrm{a}}=0$ then condition of back-EMF zero crossing detection fro $m$ the floating terminal voltage is

$$
\mathrm{V}_{\mathrm{a}}=\mathrm{V}_{\mathrm{DC}} / 2
$$

In this technique voltage of only one phase regarding DC bus voltage is sensed instead of all three terminal voltages. Zero crossing signals are generated anytime line voltage reaches to half of DC bus voltage. Commutation signal is set to logic one at the ZCD points of rising edge of the line voltage and it is set to logic zero at ZCD points of falling edge of line voltage. Co mmutation instants must be generated 30 electrical degrees after ZCD points. Other two commutation signals are generated by 120 electrical degre es delay respectively to the first signal. 


\section{SPEED CONTROL}

Speed of BLDC motor is directly proportional to its terminal voltages. A three phase voltage source inverter (VSI) is used to apply voltage to the motor (six-step algorithm). Therefore by controlling the switching of the inverter, it is possible to control the average of applied voltage to the terminals of motor. It can happen by applying a duty cycle controlled high frequency chopper signals to upper side and lower side switches.

In this paper, PWM technique is implemented to control speed of optimized sensorless drive of BLDC motor. A proportional integral (PI) controller is utilized to determine duty cycle of PWM signal according to speed error.

For BLDC motor control PWM signals can be arranged in two ways

a) One side chopping mode

b) Two side chopping mode

In one side chopping mode only one switch in conducting loop is gating the PWM signal; the other switch is always ON during the complete step. In this paper two side PWM chopping mode is used to control the duty ratio of the inverter. Here both switches in the conducting loop are gating same PWM signal. This helps to detect back emf zero crossing points easily.

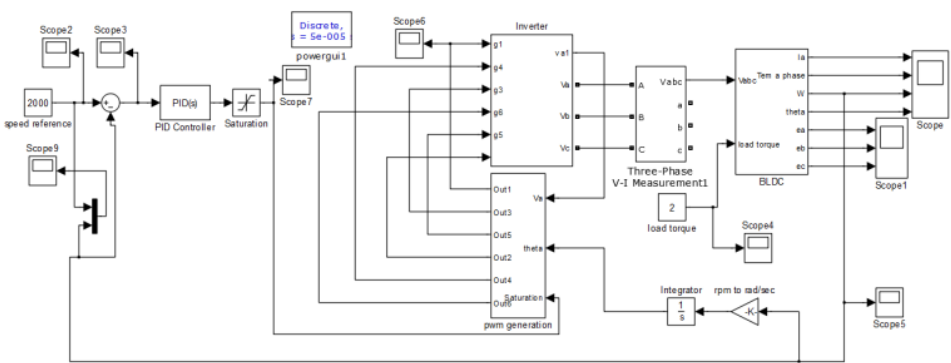

Fig. 2. Simu lation setup for sensorless speed control

\section{SIMULATION RESULTS}

The line voltage of phase A of motor is sensed with respect to the negative terminal of VSI DC bus . When line voltage of phase A reaches half dc link voltage phase A turned ON in existing scheme. In th is paper a $30^{\circ}$ time delay is introduced in order to avoid filter circuits. Other two commutation signals are generated by 120 electrical degrees delay respectively to the first signal. Three phase voltage source inverter has been modelled with MOSFETS. Carrier signal of frequency $100 \mathrm{KHz}$ is used in simulation. Simulation is run for 2 $\mathrm{Nm}$ torque load under $2000 \mathrm{RPM}$ reference speed for 0.3 seconds. Proposed sensorless commutation method of BLDC is simulated in simulink and speed control from low to high speed is achieved. The BLDC motor specification for simulation is shown in Table I.

TABLE 1. BLDC motor parameters for simu lation

\begin{tabular}{|l|c|c|}
\hline \multicolumn{1}{|c|}{ Description } & Value & Unit \\
\hline DC voltage & 400 & $\mathrm{~V}$ \\
\hline Phase resist ance & 1 & ohm \\
\hline Phase induct ance & 0.004 & $\mathrm{H}$ \\
\hline Inertia & 0.008 & $\mathrm{Kg}-\mathrm{m}^{2}$ \\
\hline Damping ratio & 0.002 & $\mathrm{~N} . \mathrm{m} . \mathrm{s}$ \\
\hline Torque constant & 1.1 & $\mathrm{~N} . \mathrm{m} / \mathrm{A}$ \\
\hline Poles & 8 & \\
\hline Back emf constant & 0.0001 & V.s/rad \\
\hline
\end{tabular}


Using two side chopping PWM control speed of the motor was varied from 600 to $10,000 \mathrm{rpm}$. A PI controller is used to control the duty cycle according to speed error. Speed and torque waveforms of BLDC are shown in Fig. 3.
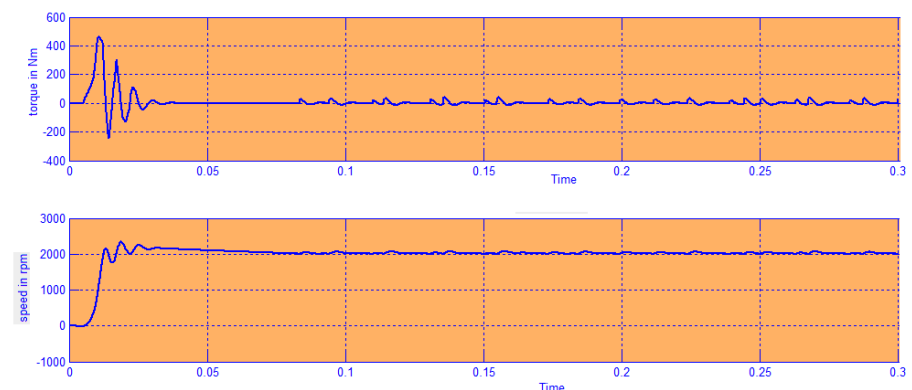

Fig. 3. Electromagnetic torque and rotor speed waveform.

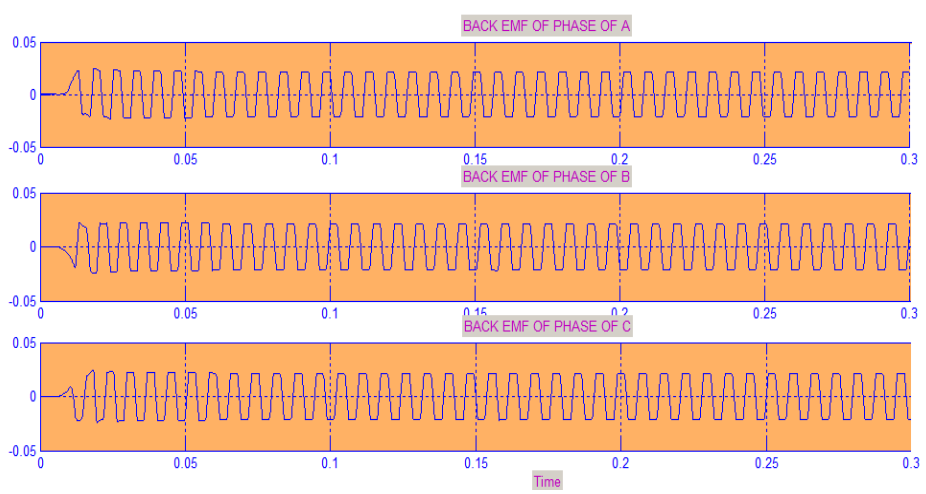

Fig. 4. Back emf waveform of 3 phases

When a BLDC motor rotates, each winding generates back electromotive Force or back EMF, which opposes the main voltage supplied to the windings according to Lenz"s Law. The polarity of this back EMF is in opposite direction of the energized voltage. Back EMF depends mainly on three factors:

- Angular velocity of the rotor

- Magnetic field generated by rotor magnets

- The nu mber of turns in the stator windings.

Once the motor is designed, the rotor magnetic field and the number of turns in the stator windings remain constant. The only factor that governs back EMF is the angular velocity or speed of the rotor and as the speed increases, back EMF also increases. The motor technical specification gives a parameter called, back EMF constant that can be used to estimate back EMF for a given speed. It can be seen that there are two zero crossing points for rising and falling edge of phase voltage each cycle; one is for rising edge and another is for falling edge. Zero crossing points of rising edge are references for commutation signal to go high (logic 1) and ZCD points of falling edge are references for commutation signal to go low (logic 0). Variations of rotor position is shown in Fig 5.

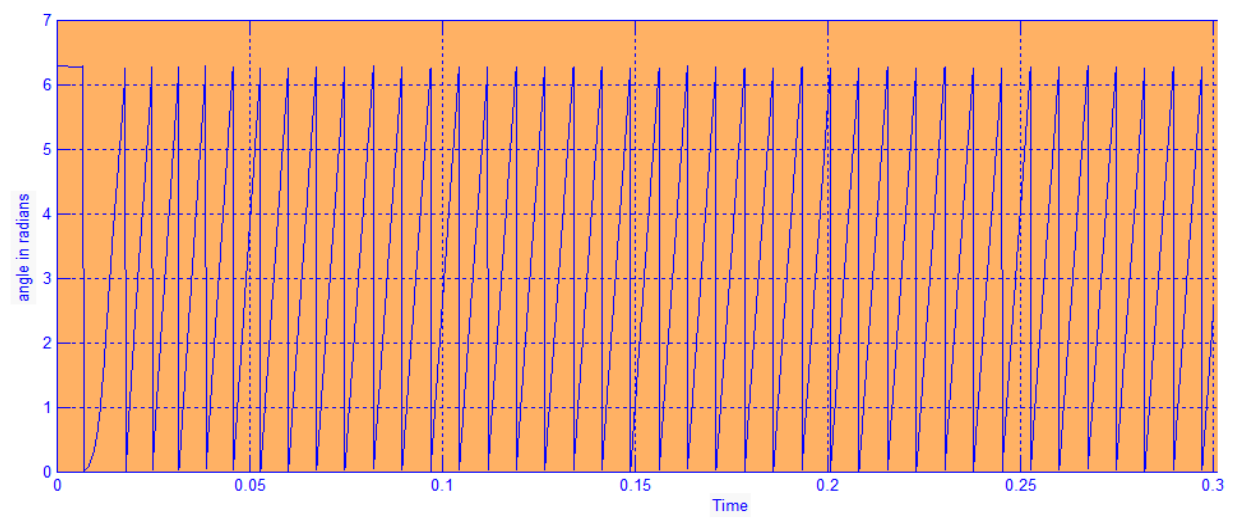

Fig. 5. Rotor position 


\section{Conclusion}

In this paper, speed control of sensorless brushless DC motor from low to high speed is achieved using two side chopping mode PWM technique. This method use the line voltage of one phase of BLDC motor instead of voltages of all three phases. Thus causing a remarkable reduction in sensing circuit components and cost of the BLDC motor drive. PWM switching technique has been implemented to control speed of BLDC motor. Two side chopping mode PWM helps to detect back emf zero crossing points easily. Proposed technique has been modelled in Simulink. Simulation results are satisfactory and prove correct performance of proposed sensorless drive and PWM speed controller of BLDC motor.

\section{REFERENCES}

[1] J. Gamazo-Real, E. V zquez-Snchez, and J. Gmez-Gil, "Position and control of brushless dc motors using sensorless techniques and application trends," Sensors, vol. 10, no. 7, pp. 6901-6947, 2010.

[2] Tashakori , M. Ektesabi, "Stability analysis of sensorless bldc motor drive using digital pwm technique for electric vehicles", IECON 2012 - 38th Annual Conference on IEEE Industrial Electronics Society, pp. 4898 - 4903 , 25-28 Oct. 2012.

[3] R.E. Bimal K Bose, "Modern Power Electronics and AC Drives", Pearson Education Publications, New Delhi, 2002, Chapter 9 , pp483-495.

[4] G.-J. Su and J. McKeever, "Low-cost sensorless control of brushless de motors with improved speed range," IEEE Transactions on Power Electronics, vol. 19, no. 2, pp. 296-302, 2004.

[5] T-H. Kim and M. Ehsani, "Sensorless control of the blde motors from near-zero to high speeds," IEEE Transactions on Power Electronics, vol. 19, no. 6, pp. 1635-1645,2004.

[6] P. Damodharan and K. Vasudevan, "Sensorless brushless de motor drive based on the zero-crossing detection of back electromotive force (emf) from the line voltage difference," IEEE Transactions on Energy Conversion, vol. 25, no. 3, pp. 661-668, 2010.

[7] Krishnan R motor "Drives Modeling, Analysis and Control', Prentice Hall of India, First Edn, 2002, Chapter 9, pp 513-615. 